\title{
Correction to: A condom's footprint - life cycle assessment of a natural rubber condom
}

\author{
Maik Birnbach $^{1} \cdot$ Annekatrin Lehmann ${ }^{2} \cdot$ Elisa Naranjo ${ }^{1} \cdot$ Matthias Finkbeiner $^{2}$ \\ Published online: 15 May 2020 \\ (C) Springer-Verlag GmbH Germany, part of Springer Nature 2020
}

\section{Correction to: The International Journal of Life Cycle Assessment https://doi.org/10.1007/s11367-019-01701-y}

The original version of this article unfortunately contained mistakes which were missed during typesetting.

The article title was incorrect. The correct title reads "A condom's footprint - life cycle assessment of a natural rubber condom".

The list of keywords was corrected.

In chapter " 2.3 " and "4" an incorrect URL was mentioned. The correct URL should read "einhorn.my/science".

The caption of Figure 1 should read "Product system studied (background processes in dashed boxes)".

The caption of Figure 2 should read "Simplified retailing channels".

Figure 3 contained incorrect data. The correct version of the figure is given below.

The reference "ChemSec (2018) 'SIN List, Thiram"” was incorrect. The correct reference should read "ChemSec (2018) 'SIN List, Thiram'. International Chemical Secretariat, Available at: https://sinsearch.chemsec.org/chemical/137-268 (Accessed 11 June 2018)".

The reference "Dresen L et al (1993) The condom-its ups and downs" was incomplete. The correct reference should read "Dresen L et al (1993) The condom - its ups and downs. University of Amsterdam, Netherlands. Available at: https:// condomerie.com/condomologie/condoomhistorie/lusten-enlasten?__store $=$ english\&__from_store $=$ nederlands (Accessed 16 Jan 2016)".

The reference "Research and Markets (2017) Condom market - global outlook and forecast 2018-2023" was incomplete. The correct reference should read "Research and Markets (2017) Condom market - global outlook and forecast 2018-2023. Dublin. Available at: https://www. researchandmarkets.com/research/pt2tf8/global_condom?w= 12 (Accessed 3 Mar 2017)".

The reference "Rubber Asia (2017) NR production down 2.7\% in 2016: ANRPC" was incomplete. The correct reference should read "Rubber Asia (2017) NR production down 2.7\% in 2016: ANRPC. Available at: https://rubberasia.com/ 2017/02/15/nr-production-2-7-2016-anrpc/ (Accessed 3 Mar 2017)".

The original article has been corrected.

The online version of the original article can be found at https://doi.org/ 10.1007/s11367-019-01701-y

Maik Birnbach

maik@einhorn.my

einhorn products GmbH, 10997 Berlin, Germany

2 Chair of Sustainable Engineering, Technical University Berlin, 10623 Berlin, Germany 


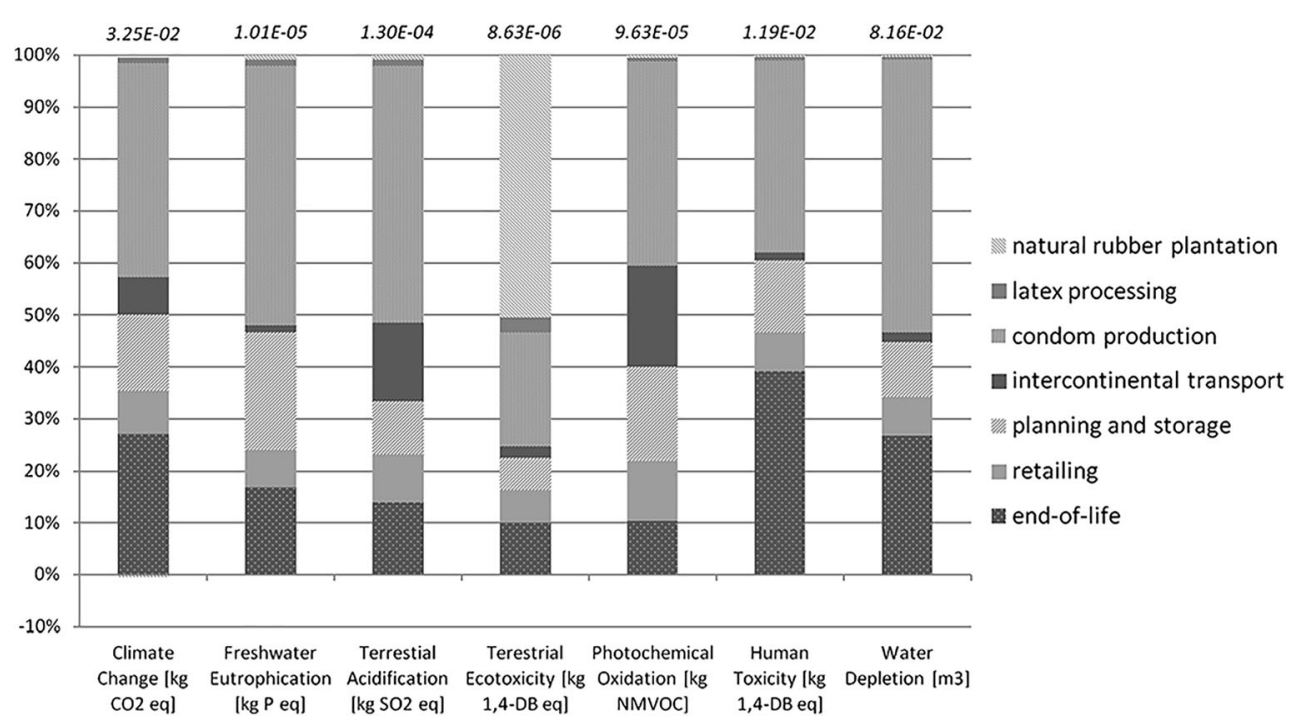

Fig. 3 